\title{
REMONTAR FRONTERAS PARA TRABAJAR \\ EN EL SUR DE MÉXICO: EL CASO DE ADOLESCENTES \\ de Guatemala en Tapachula
}

\section{Overcoming Borders to WORK in Southern Mexico: The Case of Guatemalan Adolescents in Tapachula}

\section{Martha Luz Rojas Wiesner*}

Resumen: Una combinación de disposiciones encaminadas al ordenamiento de flujos migratorios fronterizos y transfronterizos, por un lado, y de medidas relacionadas con la edad mínima para trabajar y con la "erradicación del trabajo infantil", por el otro, ha tenido diferentes efectos en la dinámica y experiencias de la movilidad internacional de adolescentes guatemaltecos que llegan a trabajar temporalmente en actividades informales en la ciudad de Tapachula, Chiapas. La aplicación de tales medidas sin considerar contextos, circunstancias y causas de la migración, así como las diferencias por edades específicas, ha incrementado los riesgos y las vulnerabilidades para migrantes menores de 18 ańos, lo que contradice el enfoque de derechos humanos que las propias autoridades expresan sobre la necesidad del reconocimiento de esta población como sujeta de derechos. En este contexto y con base en entrevistas en Tapachula, se enfatiza en los obstáculos que los adolescentes guatemaltecos deben remontar para cruzar la frontera y trabajar en esta ciudad.

\footnotetext{
* Investigadora del Departamento de Sociedad y Cultura de El Colegio de la Frontera Sur, en San Cristóbal de Las Casas, Chiapas, México. Temas de interés: migración centroamericana a México, mujeres y niñez migrantes, vulnerabilidades y procesos de inclusión de migrantes, http://orcid.org/0000-0001-7881-992X, correo e.: mrojas@ecosur.mx Fecha de recepción: 2808 17; 2a . versión: 2206 18; Fecha de aceptación: 270618. Nota del editor: se respeta la versión final del texto sugerida por la autora.
} (cc) EY-NC-ND Páginas 99-136. 
Palabras clave: migración Guatemala-México, adolescentes migrantes trabajadores, control fronterizo, erradicación del trabajo infantil, sujetos de derecho.

Abstract: A combination of legal provisions for the management of border and cross-border migration flows, on the one hand, and measures related to the minimum working age and the "eradication of child labor", on the other, have had different effects on the dynamics and experiences on the international mobility of Guatemalan adolescents who participate in the temporary informal work activities in the city of Tapachula, Chiapas. The application of such legal provisions without regard to contexts, circumstances, and causes of migration, as well as age-specific differentiations, has increased risks and vulnerabilities for migrants under the age of 18 . This situation contradicts the human rights approach that authorities themselves proclaim on the recognition of this population as a subject of rights. In this context and based on interviews in Tapachula, this article emphasizes the obstacles that Guatemalan adolescents must overcome to cross the border and work in this city.

Keywords: Guatemala-Mexico migration, adolescents migrant workers, border control, eradication of child labor, subjects of rights.

\section{Introducción}

Las medidas de control y contención migratorias de los últimos años, en México, no sólo han afectado la movilidad de personas que buscan cruzar el territorio nacional para llegar a Estados Unidos, también han tenido diferentes efectos en la dinámica y en las experiencias de movilidad internacional en su llamada "frontera sur", tanto para personas nacidas en otros países que ya están viviendo en esta región como para quienes llegan a trabajar de manera estacional o bien cotidiana a localidades vecinas o colindantes, en particular con Guatemala (ver, por ejemplo, Rojas y 
Vargas, 2014; Basok, Bélanger, Rojas y Cándiz, 2015; Rojas, 2017). Si bien este régimen migratorio restrictivo ha tenido efectos en estas distintas modalidades de movilidad, en el presente artículo se busca focalizar la atención en la de personas de 15 a 17 años cumplidos, originarias de Guatemala, que durante décadas y con distintas temporalidades han llegado a trabajar a localidades fronterizas del estado de Chiapas.

Las mayores restricciones impuestas por el actual régimen migratorio mexicano han obligado a una parte de este grupo de personas a recurrir a varias acciones para poder cruzar la línea fronteriza. Esta línea divisoria, como lo señalara Jan de Vos (2005), en distintos momentos de su historia, se ha erigido como frontera-límite, afectando la vida de personas en y de la región. ${ }^{1}$ Pero esta frontera, también "es región de encuentro de gente que lleva siglos de cruzarla en los dos sentidos y de distinta manera" (ídem: 15). La interacción cotidiana, no sólo comercial o con fines laborales o turísticos, sino además de cercanía mediante lazos de parentesco y compadrazgo en un territorio que fue cruzado por una línea internacional, incide en el tipo de percepción que se tiene sobre la frontera y el significado que cobra para quienes viven allí o en su proximidad. Hasta hace pocos ańos, tanto las personas originarias de Guatemala como las personas de localidades mexicanas vecinas no percibían el cruce fronterizo como un límite. Según Carol Girón (2010), la frontera no se concebía como demarcación y la palabra "migración” era asociada con ir a Estados Unidos; mientras que México se asociaba a lugar cercano para trabajar y obtener un ingreso para la subsistencia de la familia. Sin embargo, en los tres últimos lustros, el mayor control fronterizo y la exigencia de documentos migratorios, junto a las restricciones a la edad para la documentación migratoria independiente de personas "menores de dieciocho años", han incidido en las formas en que este grupo de personas cruza de Guatemala a México y cómo redefine la frontera y su movilidad en la región.

\footnotetext{
${ }^{1}$ Jan de Vos distinguió cinco episodios de la historia de la frontera México-Guatemala y Belice: 1. de 1528 a 1531: trazo de la primera frontera-límite; 2. de 1824 a 1842: cambio de demarcación territorial: las provincias de Chiapa y Soconusco se anexan a México; 3. de 1882 a 1895: ajuste en la demarcación internacional del periodo previo; 4. de 1981 a 1984: la frontera-límite de 1882 se convierte en frontera de seguridad, y 5. la frontera al tránsito hacia Estados Unidos (De Vos, 2005).
} 
Desde hace varios años, cuando comenzamos a estudiar la situación de las mujeres y de los "menores de dieciocho años" de Guatemala que llegaban a trabajar de manera temporal a la región Soconusco en actividades agrícolas, habíamos llamado la atención sobre el trato que, en particular, estaban recibiendo adolescentes que aún no cumplían 16 años, a quienes a mediados de la década de 2000 se les comenzó a negar el trámite migratorio correspondiente y su ingreso a México si no demostraban acompañamiento de sus progenitores, mientras que a adolescentes con 16 y 17 años se les pedía la autorización de sus progenitores para trabajar en las unidades productivas a las que se dirigían. Estas restricciones en la documentación migratoria no sólo se han enfocado en el flujo de trabajadores y trabajadoras agrícolas, sino, en general, en adolescentes de Guatemala que buscan trabajo en México. ${ }^{2}$ Hay distintas evidencias de los efectos negativos de la aplicación de estas medidas que hemos constatado durante más de una década: la producción de irregularidad migratoria, el redireccionamiento del flujo migratorio, y las mayores dificultades y riesgos que enfrenta el grupo de población en mención para llegar a localidades fronterizas de México a trabajar. Situaciones que también se pueden evidenciar en otros contextos, y para otras edades, como resultado del mayor control migratorio (ver, por ejemplo, Velasco, 2016). Aquí nos focalizamos en el caso de adolescentes entre 15 y 17 ańos cumplidos por los efectos de la combinación de las medidas ya mencionadas.

Para este artículo nos basamos en testimonios de quince adolescentes, de un total de veinte participantes, en un taller $^{3}$ que llevamos a cabo en 2012, enfocado a conocer sus experiencias de trabajo en la

\footnotetext{
${ }^{2}$ Esas restricciones, igualmente, aplican para el caso de adolescentes beliceños, en caso de registrase su presencia. Hasta ahora, el Instituto Nacional de Migración, INM, solamente expide permisos para trabajadores y trabajadoras "visitantes" de Guatemala y de Belice. Si bien se ha propuesto que se amplíe la cobertura de la Tarjeta de Trabajador Fronterizo para El Salvador y Honduras, aún no hay un acuerdo al respecto (ver CCINM, 2015).

${ }^{3}$ El taller se llevó a cabo en El Centro de Atención a Niñas, Niños y Jóvenes Migrantes - conocido como Casa de Día o Centro de Día (DIF Chiapas, s.f.)—, en la ciudad de Tapachula, con la participación de veinte niños y adolescentes: dieciocho de Guatemala, uno de México y uno de El Salvador. Cuando se realizó el taller no había mujeres menores de dieciocho ańos. Si bien ellas llegan a la Casa de Día, su número es muy bajo, de acuerdo con la información proporcionada por la directora cuando se realizó el taller (Rojas, 2014).
} 
ciudad de Tapachula. El taller es una actividad de una línea de investigación relacionada con el estudio de las características y las condiciones de vida y de trabajo de migrantes de origen guatemalteco que viven y/o trabajan en Chiapas. En este taller en especial surgieron expresiones y experiencias relativas al régimen migratorio restrictivo y a las dificultades que habían comenzado a percibir para llegar a trabajar a Chiapas. Estos adolescentes llegan a la ciudad de Tapachula, por temporadas cortas o largas, para ocuparse en actividades caracterizadas por la informalidad, ya sea por el tipo o naturaleza de la unidad económica en la que se emplean o por el tipo de trabajo que desempeñan (OIT, 2014).

$\mathrm{Al}$ momento del taller, los quince adolescentes tenían entre 15 y 17 años cumplidos, edades que según la legislación mexicana y las normas laborales internacionales son admitidas para poder trabajar. En México, la edad mínima para trabajar es quince años. Esta edad mínima puede ser diferente en otros contextos, aunque el rango que va de esa edad mínima laboral hasta cumplir dieciocho ańos puede tener condicionantes para trabajar, como sucede en México. Estos condicionantes deben ser acatados por los empleadores y ser supervisados por las autoridades laborales, pero cuando se trata de migrantes, las autoridades migratorias también intervienen al establecer los requisitos para la expedición de documentos migratorios con autorización para trabajar. Si bien en 2018 estas personas ya tienen un poco más de veinte ańos, nos interesa llamar la atención sobre los obstáculos aún vigentes para adolescentes de Guatemala de 15, 16 y 17 años que llegan a trabajar a localidades fronterizas de México. Aunque la autoridad migratoria mexicana reconoce que este grupo de migrantes tiene derechos (Unicef México e INM/DGPMV, 2013), la imposición de restricciones para su ingreso a México resulta contraria a ese discurso. Con estas restricciones, no sólo se produce irregularidad migratoria, como ya lo mencionamos, también movilidad clandestina (Brachet, 2018). La exigencia de documentos migratorios de facto produce categorías de personas - migrantes/no migrantes; en situación migratoria regular/irregular, entre otras-, que han sido cuestionadas por contravenir la obligatoriedad en la garantía y protección de derechos de la niñez y la adolescencia, independientemente de su situación migratoria. 
La preocupación de las autoridades mexicanas por: 1. el control migratorio, 2. la observancia rígida de la edad mínima para trabajar, y 3. la aplicación de las disposiciones relativas a la "erradicación del trabajo infantil", sin un análisis específico del contexto, de las circunstancias y de las causas de la migración, tiene efectos contrarios al reconocimiento de la niñez y de la adolescencia migrante como sujetas de derechos, en especial si se considera que personas de estos grupos de edad llegan a trabajar a México como una estrategia de sobrevivencia familiar.

Este artículo se estructura en cuatro partes. En primer lugar, se alude a la definición de adolescencia, como parte del concepto más amplio de niñez, pero enfatizando en la clasificación por edades, que se ha tomado como referente por las autoridades de trabajo y de migración para definir la edad mínima para el trabajo y la edad para la documentación migratoria de manera autónoma. En segundo lugar, a partir de la revisión de la literatura sobre el tema, se destaca la participación de niñas, niños y adolescentes en la migración, como sujetos sociales de derechos. con énfasis en su agencia en estos procesos, en particular cuando hay restricciones para su movilidad. En tercer lugar, se señalan elementos relativos al control migratorio y a la regulación de la edad para trabajar que inciden en las experiencias de migración de adolescentes de Guatemala. En cuarto lugar, se abordan algunas de las experiencias en la migración de adolescentes guatemaltecos en Tapachula y las estrategias que usan para poder trabajar en esta ciudad, en una época en que la gestión migratoria se ha enfocado a la administración de flujos migratorios. Finalmente, se presentan algunas reflexiones - y no conclusiones — con miras a revisar las formas como se diseñan y aplican las normas que se supone deben estar dirigidas a la protección y al reconocimiento de migrantes como "sujetos de derechos".

\section{Adolescentes y las clasificaciones por edad}

Normativamente, en muchos países, incluidos México y Guatemala, los dieciocho años marcan el comienzo de la "vida adulta", una "etapa" de la vida en la que jurídica y socialmente se reconoce que las personas ya pueden tomar decisiones, que son responsables de sus actos, que se convierten en "ciudadanas/os" con derechos y obligaciones, entre otras 
asignaciones sociales. En ese sentido, los dieciocho años constituyen "la edad" límite o frontera que no sólo delimita, sino que demarca socialmente un momento en la vida de las personas a partir del cual son admitidas en el mundo de la adultez. En ese mundo se asume que las personas están "completas" o "listas" para la vida (Cruz, 2009: 171). A quienes aún no cumplen esa edad se les categoriza como "menores de edad" o, simplemente, como "menores", concepto este último que ha recibido críticas por estar asociado a un enfoque tutelar mediante el cual se concibe a la niñez como "objeto de protección" ${ }^{4}$; mientras que se aboga por aludir a este grupo como "niños, niñas y adolescentes" por considerar que se inscribe en un enfoque de "protección integral de derechos" que les concibe como "sujetos de derechos".

Los "menores de dieciocho años" constituyen el grupo que ha sido definido de manera genérica como niñez, de acuerdo con la Convención de los Derechos del Niño [y de la Niña ${ }^{6}, \mathrm{CDN}$, rango de edad que se toma como referencia para la aplicación de ciertos principios para la protección de derechos. ${ }^{7}$ En este amplio rango, se suele distinguir entre niñez y adolescencia, ${ }^{8}$ aunque sigue habiendo un uso genérico de "niñez” para aludir al grupo en mención. Para el caso de la adolescencia,

\footnotetext{
${ }^{4}$ Según Nuria González (2012), la confusión ha derivado de la equiparación entre “menor" e "incapaz". Al respecto señala que "una cosa es afirmar que el menor tiene per se determinadas limitaciones y otra muy diferente, admitir que es un incapaz" (ídem: 58), por lo que no hay razón para omitir su uso, considerando, además, que el término "menor" se consigna en varias convenciones internacionales desde un enfoque de derechos, aunque recomienda su uso en plural, para reconocer las diferencias por edades en este grupo de población (ídem: 170).

${ }^{5}$ En términos demográficos, cuando se hace referencia a la composición o clasificación por grandes grupos de edades, se alude a este grupo mencionando la edad que limita el intervalo: "menores de 18 años". Aquí usaremos de manera indistinta "menores de dieciocho años" y "niños, niñas y adolescentes" cuando se haga referencia al grupo de edad en mención. Cuando aludamos a la revisión bibliográfica usaremos "niñez", de acuerdo con el uso que hagan los autores del texto. Hay países en los que este grupo puede estar definido en un rango diferente de edades, o bien el concepto mismo de adolescencia como una etapa de transición hacia la adultez puede ser concebida de otro modo, por lo que se prefiere el uso genérico de "niñez".

${ }^{6}$ Adoptada el 20 de noviembre de 1989, entrada en vigor el 2 de septiembre de 1990 y ratificada por México el 21 de septiembre de 1990 (Naciones Unidas, s.f.).

${ }^{7}$ Según el artículo 1 de la CDN, el rango puede ser diferente y dependerá de la edad que por ley se establezca como mayoría de edad.

${ }^{8}$ La Ley para la Protección de los Derechos de Niños, Niñas y Adolescentes, LPDNNA, por ejemplo, hace esta distinción. Según el artículo 2, son adolescentes quienes tengan entre 12 y 17 años cumplidos (LPDNNA, 2010).
} 
instituciones, como la Organización Mundial de la Salud, OMS, o el Fondo de Naciones Unidas para la Infancia, Unicef, distinguen entre la adolescencia temprana - de 10 a 14 años—y la adolescencia tardía —de 15 a 19 años— (OMS, s.f.; Unicef, 2011). La delimitación por edad en estricto sentido es arbitraria. Cualquiera de estos grupos no es homogéneo, hay variaciones en cada sociedad y en cada contexto histórico, por lo que no se pueden hacer generalizaciones ni tratar a estas agrupaciones como si fueran unidades (Ariza, 2005).

Aquí hacemos referencia a este tipo de clasificaciones por edad debido a nuestro interés sobre las restricciones derivadas del establecimiento de una edad mínima para trabajar, así como de los condicionantes según edad para llevar a cabo trámites migratorios con autonomía. En otras palabras, buscamos cuestionar la rigidez con la que se ha aplicado este tipo de criterios que, bajo el argumento de la edad y de la "protección de los menores", limita las oportunidades para adolescentes guatemaltecos de entre 15 y 17 ańos cumplidos que buscan mejorar en algo sus condiciones de vida con un trabajo temporal en México. De acuerdo con el Decreto por el que se reforma la fracción III del apartado A del artículo 123 de la Constitución Política de los Estados Unidos Mexicanos (2014) y el Decreto por el que se reforman y derogan diversas disposiciones de la Ley Federal del Trabajo, en materia de trabajo de menores (2015), estos adolescentes cumplen con la edad mínima para trabajar en México, pero, además, no están realizando un trabajo peligroso, tal como lo define la OIT (s.f.), como lo analizaremos más adelante. Desde nuestro punto de vista, la aplicación estricta de disposiciones por criterios de edad, en una interpretación sumamente rígida, sin tomar en cuenta aspectos contextuales y culturales, así como principios enunciados en las propias disposiciones, e incluso en las propias recomendaciones de la OIT, lejos de disuadir a estos adolescentes a no migrar, los expone a una mayor vulnerabilidad a la explotación laboral, a la discriminación, a la inseguridad y a distintas formas de precariedad. 


\section{Adolescentes en la migración como sujetos sociales de derechos}

En México, como en otros países, desde hace algunos años ha habido una preocupación por la migración de niños, niñas y adolescentes, fundamentalmente porque se ha producido un incremento notorio de migrantes de estos grupos de población que viajan solos o sin la compañía de un familiar mayor de dieciocho años; ${ }^{9}$ situación que se presume los expone a distintas amenazas y, por tanto, a distintas formas de vulnerabilidad, aunque hay que decir que en determinados territorios y contextos esta compañía no necesariamente los exime de estos peligros, pues las posibilidades de la protección han sido seriamente restringidas. ${ }^{10}$

De manera similar al estudio de la migración femenina, sólo hasta hace poco el estudio de la migración de niños, niñas y adolescentes comenzó a constituirse en un área de interés o de conocimiento en sí misma, no sólo desde la academia, sino desde organizaciones de la sociedad civil y desde instituciones que trabajan en el tema. El poco interés era resultado del tipo de enfoque usado para su análisis. Según Dobson (2009), en algunos estudios se ha tratado a la niñez migrante como una extensión de la migración de adultos, como parte de un grupo familiar, y como si fuese "un equipaje" o una cosa transportada por una persona adulta, por lo que se estudiaba de manera asociada a la migración de esta última población.

\footnotetext{
${ }^{9}$ En el caso de México, el acompañamiento o no de una persona menor de edad es captada en las estadísticas migratorias mediante la "condición de viaje" en los registros de las llamadas "presentaciones" —en otros momentos conocidas como "aseguramientos" o "alojamientos" - y de las "devoluciones" (ver UPM, s.f.).

${ }^{10}$ A nivel nacional, la desagregación por grandes grupos y sexo se comenzó a publicar a partir de 2007 en el portal electrónico del Centro de Estudios Migratorios del INM. Desde esa fecha, la población menor de dieciocho años, además, es desagregada en dos grandes grupos: "de 0 a 11 años" y "de 11 a 17 años". Sin embargo, la condición de viaje — “acompañados" y "no acompañados" - solamente se publicó para el primero de estos dos grupos. Hasta 2010, este desglose incluiría a ambos grupos. Como ilustración, entre 2010 y 2016, la autoridad migratoria mexicana llevó a cabo un acumulado de 125,664 aseguramientos o presentaciones de menores de dieciocho ańos, de los cuales la mitad $-49.9 \%=62,644$ - es sin acompańamiento. De este total, $88 \%$ se relaciona con adolescentes de 12 a 17 ańos. En este último caso, el incremento ha sido notorio: de 2,137 eventos en 2010, aumentó a 5,297 en 2013, hasta llegar a 17,911 en 2015 (cálculos propios a partir de los Boletines Estadísticos de UPM, s.f.).
} 
El marco jurídico internacional ${ }^{11}$ que hace referencia a niños, niñas y adolescentes — de manera genérica, "niñez" - ha incidido en la manera de conceptualizar a la población migrante en estos grupos de edad (Gallo, 2005; Bhabha, 2008; Esser et al., 2016), lo que ha contribuido a cambiar la visión tutelar o asistencialista hacia una visión que los considera como sujetos de derechos humanos (Gallo, 2005: 139). Los principios en los que se fundamenta este marco jurídico como son el derecho a la no discriminación, el derecho a la vida y al desarrollo, y el derecho a ser escuchados y a la participación, así como el interés superior de la niñez, entre otros principios fundamentales, han contribuido a una perspectiva que, en el caso de la migración, se centra en niños, niñas y adolescentes, independientemente de su estatus migratorio y de la modalidad de su migración (Gallo, 2005; Bhabha, 2008; Chávez y Menjívar, 2010; Boehm et al., 2011; Beazley, 2015). Este enfoque no ha estado exento de críticas, en especial, en cuanto a la aplicación de las disposiciones de la CDN, lo que ha derivado en distintas observaciones del Comité de los Derechos del Niño, como las relativas al derecho a la participación (núm. 12) ${ }^{12}$ y a los derechos de la niñez indígena (núm. 11). ${ }^{13}$

En el análisis de los procesos migratorios en los que participan niños, niñas y adolescentes, la literatura en el tema se ha enfocado en las experiencias en los lugares de origen, en los trayectos hacia algún destino — sin que éstos sean unidireccionales-y en los lugares de destino, así como en las interacciones que se producen entre dichos territorios (ver, por ejemplo, Casillas, 2006; Fuentes y Moreno, 2008; Galindo, 2009; Girón, 2010; Caballeros, 2011; Valdéz-Gardea, 2011). En la última década en particular, ha habido una creciente preocupación por las experiencias en el tránsito hacia lugares en los que la población en estos grupos de edades busca algún tipo de seguridad para sus vidas, enfatizado

\footnotetext{
${ }^{11}$ En particular, la Convención sobre los Derechos del Niño, CDN, y la Convención Internacional sobre la Protección de los Derechos de todos los Trabajadores Migratorios y sus Familias, CDTMF.

${ }^{12}$ La aplicación al derecho a la participación —artículo $12, \mathrm{CDN}$ - ha sido objeto de críticas, las cuales se vinculan con la consideración de la niñez y la adolescencia como actores sociales y con su capacidad de agencia (Castro et al., 2009).

${ }^{13}$ A la fecha, la CDN tiene 31 observaciones generales del Comité de los Derechos del Niño, que buscan orientar a los Estados en su aplicación (ver OHCHR, s.f.).
} 
sobre los riesgos y las situaciones de vulnerabilidad que enfrentan y, al mismo tiempo, llamando la atención sobre los retos para su protección (ver, por ejemplo, Unicef, 2011; Chávez y Menjívar, 2010; Bhabha, 2011b; Ceriani, 2013; Musalo, Ceriani y Frydman, 2015). Varios estudios se enfocan en los factores contextuales que facilitan, motivan e involucran a niños, niñas y adolescentes en la migración; sin embargo, se ha llamado la atención sobre la poca importancia que se ha dado al análisis de la capacidad de acción, la agencia y la elección de este grupo de población, que incluye a los adolescentes de nuestro interés (Bhabha, 2008 y 2011 a; Dobson, 2009; Boehm et al., 2011; Esser et al., 2016).

Según Boehm et al. (2011), los enfoques analíticos en los estudios de niños, niñas y adolescentes migrantes buscan una mayor comprensión de estas experiencias y del papel que juegan las instituciones, la comunidad, la familia y el Estado en las "rupturas" cotidianas que ocasiona la migración, así como en la construcción y negociación de la agencia de niños, niñas y adolescentes en su propia movilidad o en la de otros integrantes de la familia (Boehm et al., 2011; ver también, Tyrrel, 2011). Estos cambios se inscriben en un debate más amplio en los estudios sobre niños, niñas y adolescentes llevados a cabo por la sociología, la psicología y la investigación en educación que habían instrumentalizado a este grupo de población y se habían centrado en los procesos de crecimiento o en el cambio hacia la adultez (Esser et al., 2016). En dichos debates se ha cuestionado el uso del concepto de agencia, así como de lo que implica pensar en niños, niñas y adolescentes como "actores sociales”, en particular si no se les concibe como personas histórica y socialmente situadas y, además, interdependientes (Esser et al., 2016).

Niñas, niños y adolescentes se involucran en distintas formas y modalidades de los procesos migratorios, ya sea motivando estos procesos, como migrantes que viajan como parte de un grupo familiar, o bien como migrantes por cuenta propia o independiente (Bhabha, 2008; Yaqub, 2009; Boehm et al., 2011). Esta participación se ve afectada por medidas restrictivas a la movilidad, las cuales tienen distintas repercusiones. En estos procesos, niñas, niños y adolescentes emplean estrategias relacionadas con sus vidas y con su entorno, basadas en la reflexividad consciente de sus acciones, esto es, del 
conocimiento que tienen de sus acciones y del contexto en el que éstas se desarrollan (Giddens, 1995). En Basok et al. (2015), señalábamos que mientras la noción de agencia destaca la capacidad de los actores para la acción, ésta no explica el proceso mediante el cual las personas se conviertan en agentes de sus propios intereses, por lo que recurrimos a la noción de "técnicas del yo»" ${ }^{14}$ de Foucault, las "que permiten a los individuos efectuar, por cuenta propia o con la ayuda de otros, cierto número de operaciones sobre su cuerpo y su alma, pensamientos, conducta, o cualquier forma de ser, obteniendo así una transformación de sí mismos con el fin de alcanzar cierto estado de felicidad, pureza, sabiduría o inmortalidad" (Foucault, 2008: 48). Estas técnicas del yo implican formas de aprendizaje y modificaciones de sí mismo, tanto en habilidades como en actitudes. Así, se confronta la imposición de medidas restrictivas derivadas del ejercicio de poder del Estado mexicano que limita la movilidad de adolescentes como trabajadores migrantes. Frente a esta visibilización estatal que dirige su atención al control del mencionado grupo poblacional, dicho grupo despliega mecanismos de invisibilidad.

Los mecanismos de invisibilidad-visibilidad pueden adquirir distintas formas, no necesariamente como una estrategia desplegada como producto de la agencia de sujetos sociales, sino también como dispositivos que responden a varios imperativos, por ejemplo, a la aplicación de determinadas disposiciones jurídicas o medidas, lo que hace que en ciertas circunstancias y determinados espacios alguien cobre presencia, pero en otras permanezca invisibilizado (Rojas y De Vargas, 2014). Cuando se habla de invisibilidad, entonces, se hace referencia a varias situaciones, pero aquí nos referiremos a la invisibilidad como estrategia de poder, como el arte de pasar desapercibido, pero también de moverse a otro lugar sin ser notado, como formas de resistencia y de confrontación silenciosa a un imperativo que restringe su movilidad y la posibilidad de trabajar debido a su edad. Desde la filosofía social

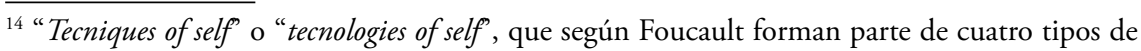
tecnologías que los individuos usan para entenderse a sí mismos: 1. tecnologías de producción, 2. tecnologías de signos, 3. tecnologías del poder, y 4. tecnologías del yo, que "casi nunca funcionan de modo separado, aunque cada una de ellas esté asociada con algún tipo de dominación" (Foucault, 2008: 48). 
crítica, la invisibilidad es "una categoría hermenéutica que se hace cargo de la interpretación de un fenómeno contradictorio que consiste en existir, en ser-ahí y, al mismo tiempo, en no ser visto/percibido u oído/escuchado" (Bourdin, 2010: 17). Estas estrategias, sin embargo, no están exentas de la exposición a riesgos y al incremento de distintas vulnerabilidades (Fuentes y Mena, 2008; Caballeros, 2011; Rojas y Caballeros, 2015).

\section{Régimen migratorio y regulación laboral}

En los episodios históricos de la frontera de México con Guatemala y Belice que Jan de Vos distinguió (ver nota de pie de página 3), la producción de la demarcación internacional ha tenido sus propias especificidades: en los tres primeros episodios, la línea divisoria se mueve para delimitar territorios; en los dos últimos esa línea ya establecida se vuelve objeto de preocupación del gobierno mexicano debido al notorio cruce de personas, en particular, desde territorio guatemalteco. Las preocupaciones por la seguridad nacional de la década de 1980 se exacerbaron y adquirieron otra dimensión a partir de los años noventa debido al tránsito fronterizo con la finalidad de llegar a Estados Unidos (De Vos, 2005). Con esta mirada histórica, la llamada frontera sur de México cobra distintos significados. En las tres últimas décadas, para dicha región, se evidencia lo que algunos autores, desde un enfoque constructivista, dicen debe concebirse como un régimen fronterizo y no sólo como una frontera: "[e]sto involucra no solo la lógica gubernamental sino también la producción de fronteras desde y con una perspectiva de migración” (Casas-Cortés et al., 2014: 15). Desde este enfoque, la migración es una fuerza activa que desafía, cruza y reestructura la frontera, que "constituye un sitio de constante encuentro, tensión, conflicto, y contestación” (ibídem).

Desde la década del año 2000, en México se ha insistido en la necesidad de una política integral en materia migratoria que supere el enfoque de gestión de flujos migratorios (ver, por ejemplo, Sin Fronteras, 2008). Sin embargo, dicha perspectiva prevalece, aunque se haya avanzado en una Ley de Migración y en otras disposiciones (ver Decreto por el que se expide la Ley de Migración, 2011). El "ordenamiento" de 
la migración, lejos de facilitar trámites y procesos administrativos, ha impuesto requisitos que no son fáciles de cumplir para muchas personas (Basok y Rojas, 2017). En general, para el caso que nos ocupa, las medidas de control y contención de la migración se han entrecruzado con la rígida aplicación por parte del Instituto Nacional de Migración, INM, de las disposiciones de la Organización Internacional del Trabajo, OIT, relativas a la erradicación del trabajo infantil, las cuales se vinculan con el Convenio sobre las peores formas de trabajo infantil, 1999 -Convenio 182 - y con el Convenio sobre la edad mínima, 1973 - Convenio 138- el primero ratificado por México en el año 2000 y el segundo en el año 2015. A estas disposiciones se sumaban los compromisos de México con el Protocolo de las Naciones Unidas para Prevenir, Reprimir y Sancionar la Trata de Personas, Especialmente Mujeres y Niños, que fue ratificado en 2003 y que obligaba al país a generar políticas inmediatas y medidas de combate a este delito garantizando la protección de las víctimas.

Esa combinación de disposiciones produjo una visibilización para las autoridades migratorias mexicanas de las personas "menores de dieciocho años" originarias de Guatemala, que venían a trabajar a Chiapas durante la década del año 2000. En 2003, a unos meses de que la OIT estableciera el Día mundial contra el trabajo infantil, ${ }^{15}$ la Delegación Regional del INM en Chiapas restringió el ingreso al país de personas menores de catorce ańos procedentes de Guatemala que llegaban a trabajar o a buscar trabajo de manera temporal en dicha entidad; la restricción también incluía a quienes tuvieran la edad, pero no contaran con el permiso de los padres mediante una carta certificada. ${ }^{16}$ Hasta la actualidad, estos requisitos se siguen aplicando, aunque con un ajuste en la edad mínima para trabajar, que se supone debería ser de quince años, en concordancia con la ratificación del gobierno mexicano del Convenio 138 de la OIT relativo a la edad mínima para la admisión al empleo.

La Ley Federal del Trabajo (LFT, 2015) vigente establece la prohibición de la "utilización del trabajo de los menores de quince

\footnotetext{
${ }^{15}$ Que se conmemora el 12 de junio.

${ }^{16}$ Notas de entrevista de Martha Rojas y Hugo Ángeles al Delegado Regional del INM en Chiapas, Javier Miguel Bolańos, en 2003.
} 
años”, consignada en la fracción III del artículo 123 constitucional $^{17}$ y, además, impone restricciones para el trabajo de mayores de quince años, pero menores de dieciocho, estableciendo lo siguiente:

Las personas mayores de quince, pero menores de dieciséis años requieren autorización de sus padres o tutores ${ }^{18} \mathrm{y}$, a falta de ellos, del sindicato al que pertenezcan, de la Junta de Conciliación y Arbitraje, del Inspector del Trabajo o de la Autoridad Política (artículo 22).

Se prohíbe utilizar el trabajo de personas mayores de quince años, pero menores de dieciocho que no hayan terminado su educación básica obligatoria, con excepción de los casos que apruebe la autoridad laboral correspondiente y en los que considere que hay compatibilidad entre los estudios y el trabajo (artículo 22 bis).

Se requiere que los mayores de quince, pero menores de dieciocho ańos obtengan un certificado médico que acredite su aptitud para el trabajo y se sometan a los exámenes médicos que periódicamente ordenen las autoridades laborales correspondientes (artículo 174).

Aunque el INM no es una instancia laboral, a la hora de la solicitud de un documento migratorio con permiso laboral interviene en ese ámbito. Así, para el trámite de una Tarjeta de Trabajador Fronterizo, TTF, los lineamientos establecen que es "[a]plicable a nacionales

${ }^{17}$ En apego al Decreto por el que se reforma la fracción III del apartado A del artículo 123 de la Constitución Politica de los Estados Unidos Mexicanos, publicado en el DOF el 17 de junio de 2014, se modificó la edad mínima para trabajar en los siguientes términos: “[q]ueda prohibida la utilización del trabajo de los menores de quince ańos. Los mayores de esta edad y menores de dieciséis tendrán como jornada máxima la de seis horas." (Artículo 123, A, III). En 1931 esta edad mínima era de doce años, en 1962 de catorce años, y en 2015 de quince ańos (Marquet, 2014; Decreto por el que se reforman y derogan diversas disposiciones de la Ley Federal del Trabajo, en materia de trabajo de menores, 2015).

${ }^{18}$ Resaltado de la autora. Valga agregar que este criterio era aplicado por el INM cuando la edad mínima para trabajar era de 14 años. En 2010, Carol Girón hacía referencia al trámite de la FMTF, señalando: "[e]n este último caso, los niños, niñas y adolescentes pueden realizar el trámite directamente siempre y cuando hayan cumplido los 16 años de edad y cuenten con un documento que lo demuestre y permiso de los padres" (Girón, 2010: 253).

julio-diciembre 2018, núm. 11 EntreDiversidades ISSN: 2007-7610 
guatemaltecos y beliceños que tengan 16 años $^{19}$ o más, cuenten con una oferta de empleo y soliciten la condición de estancia de visitante trabajador fronterizo" (Lineamientos para trámites y procedimientos migratorios, 2012, artículo 77).

Para las personas menores de 18 años, en específico de Guatemala, se estipulan como requisitos: ${ }^{20}$

1. "Presentar certificado de nacimiento cuya expedición no sea mayor a seis meses" 21 ;

2. "Oferta de empleo en escrito libre suscrito por el empleador o por su representante legal, que previamente haya obtenido constancia de inscripción de empleador";

3."Los nacionales guatemaltecos mayores de 16 y menores de 18 años, acompañados por un tercero o viajen solos, presentarán adicionalmente a los requisitos señalados, documento en el que conste la autorización para trabajar en territorio nacional y salir del mismo otorgado por las personas que ejercen sobre ellos la patria potestad o la tutela ante notario público"22;

4. "Comprobante del pago de derechos correspondiente en términos de la Ley Federal de Derechos"23.

\footnotetext{
${ }^{19}$ Resaltado de la autora para enfatizar la edad mínima que establece el INM para la expedición de TTF.

${ }^{20}$ Los requisitos para personas de origen beliceño y de origen guatemalteco difieren levemente. A las primeras no se les pide Documento Personal de Identificación — por ser el documento de identidad de Guatemala_; en el caso de Belice, la autorización de quienes ejercen la patria potestad debe estar certificada por un juez de paz, mientras que en el caso de Guatemala por un notario público.

${ }^{21}$ Este requisito también es aplicable a los casos de trabajadores y trabajadoras que viajan con sus hijos e hijas menores de 18 ańos, pues se debe comprobar el parentesco, incluyendo el vínculo de matrimonio o unión libre, si el trabajador o trabajadora viaja en compañía de su familia (Lineamientos para trámites y procedimientos migratorios, 2012, artículo 77).

${ }^{22}$ Valga decir que el requisito de la autorización ante notario público también aplica para el caso del trámite de una Tarjeta de Visitante Regional (Lineamientos para trámites y procedimientos migratorios, 2012, artículo 74).

${ }^{23}$ En julio de 2017, el costo de una TTF era 332 pesos, el cual se puede exentar si el trabajador o la trabajadora demuestra, con una carta oferta de empleo, que ganará menos del salario mínimo (LFD, 2016).
} 
Para adolescentes independientes que no tienen una oferta de trabajo y/o que sus progenitores/tutores viven en localidades lejanas de un centro urbano donde haya un notario público, pero que, además, no cuentan con recursos para la carta de autorización certificada por este funcionario, el obtener una TTF resulta prácticamente imposible; pero optar por una Tarjeta de Visitante Regional, TVR, tampoco es muy viable para adolescentes que viven en aldeas lejanas, quienes también deben cumplir con el requisito de la carta de autorización ya mencionada. Incluso para adolescentes que buscan trabajar con un empleador registrado — por ejemplo, en actividades agrícolas—, los requisitos no siempre se pueden cumplir.

¿A qué se debe esta aplicación de requisitos tan rígida para menores de edad? ¿Se trata de velar por el cumplimiento de las disposiciones de la OIT relativas a la erradicación del trabajo infantil y de las peores formas de este tipo de trabajo? Pero ¿cómo se vinculan estas preocupaciones con los requisitos para la documentación migratoria? Si las respuestas a estos interrogantes están relacionadas con las preocupaciones por el trabajo infantil ¿cuál es su definición? Y ¿qué implicaciones tienen las medidas para su erradicación en la búsqueda de oportunidades de adolescentes que tradicionalmente han llegado a centros urbanos como Tapachula para trabajar?

$\mathrm{Al}$ revisar las publicaciones de la OIT es posible identificar que el concepto de trabajo infantil ha creado confusiones. Incluso, este organismo internacional ha tenido que elaborar manuales de orientación para las empresas con el fin de "[e]ntender las situaciones de trabajo infantil” (OIT y OIE, 2016). Según la OIT y la Organización Internacional de Empleadores, OIE:

El trabajo infantil abarca todas las formas de trabajo inaceptables realizadas por los niños [y las nińas]. Se trata de trabajo que expone a los nińos [y a las niñas] a daños o abusos porque: 1) puede dificultar la educación y el pleno desarrollo del niño [y de la niña] — debido a la edad del niño [y de la nińa]—; y/o 2) pone en peligro el bienestar físico, mental o moral del niño [y de la niña] — dada la naturaleza del trabajo- (OIT y OIE, 2016: 17). 
Así entendido, estas mismas organizaciones advierten que "trabajo infantil" no es sinónimo de "trabajo llevado a cabo por personas menores de dieciocho años":

No todo el trabajo realizado por los nińos es trabajo infantil. Millones de personas jóvenes por encima de la edad minima correspondiente trabajan, remuneradas o no, de manera legítima, apropiada para su edad y madurez y formando parte de su socialización y de la transición de la escuela al trabajo. Trabajando, estos jóvenes aprenden a asumir responsabilidades, adquieren competencias, contribuyen a los ingresos y el bienestar de su familia o a los suyos propios, y contribuyen a la economía de su país (OIT y OIE, 2016: 17). ${ }^{24}$

Lo que se puede deducir es que "trabajo infantil" se usa como adjetivo calificativo o, si se quiere expresar de otra forma, hay que identificar qué actividad califica o no como "trabajo infantil”. En México, citando a la OIT, el Consejo Nacional para Prevenir la Discriminación, señala:

Para calificar o no de "trabajo infantil" a una actividad específica habrá que valorar entonces, además de la edad, "el tipo de trabajo en cuestión y la cantidad de horas que le dedica, las condiciones en que lo realiza y los objetivos que persigue cada país. La respuesta varía de un país a otro y entre uno y otro sector" (Conapred, 2010: 5).

La erradicación del trabajo infantil y de las peores formas de este tipo de trabajo no se logra imponiendo requisitos migratorios rígidos para personas "menores de dieciocho años" que buscan trabajar en México. Los estándares internacionales consideran las situaciones en las cuales se puede flexibilizar la edad o se reconoce la autonomía de las personas adolescentes en la búsqueda de oportunidades laborales, diciendo que los "menores de edad sin acompańamiento" enfrentan distintos riesgos, por lo cual se deben encaminar esfuerzos para garantizar el acceso y la

\footnotetext{
${ }^{24}$ Resaltado de la autora, para enfatizar que las críticas las enfoca a la manera como se aplica el concepto para las personas con la edad mínima para trabajar. La propia OIT alude a la posibilidad de "trabajo ligero" para personas por debajo de esta edad mínima, siempre que las leyes del país lo permitan, pero esa discusión amerita otro espacio.
} 
realización de derechos, independientemente de su nacionalidad y estatus migratorio.

Al respecto, el Comité de los Derechos del Niño, en 2005, emitió la Observación General No. 6. Trato de menores no acompañados y separados de su familia fuera de su pais de origen, mediante la cual se enfatiza que:

Las obligaciones del Estado en virtud de la Convención [de los Derechos del Nińo] se aplican con referencia a todos los menores que se encuentren dentro de su territorio y a los que estén por otro concepto sujetos a su jurisdicción (art. 2). Estas obligaciones a cargo del Estado no podrán ser arbitraria y unilateralmente recortadas ... Por otra parte, las obligaciones del Estado de acuerdo con la Convención se aplican dentro de las fronteras de ese Estado, incluso con respecto a los menores que queden sometidos a la jurisdicción del Estado al tratar de penetrar en el territorio nacional. Por tanto, el disfrute de los derechos estipulados en la Convención no está limitado a los menores que sean nacionales del Estado Parte, de modo que, salvo estipulación expresa en contrario en la Convención, serán también aplicables a todos los menores — sin excluir a los solicitantes de asilo, los refugiados y los niños migrantes- con independencia de su nacionalidad o apatridia, y situación en términos de inmigración (Naciones Unidas, 2005: 7). ${ }^{25}$

Dicho comité define como "menores no acompañados" a quienes están separados/as de ambos padres y otros parientes y no están al cuidado de una persona adulta a la que, por ley o costumbre, incumbe esa responsabilidad. Por su parte, se refiere a "menores separados" como aquellas personas que están separadas de sus padres o de sus tutores legales o habituales, pero no necesariamente de otros parientes (Naciones Unidas, 2005: 6). La Observación No. 6 permite identificar un espectro amplio de situaciones, que no se restringen a la "condición de viaje", mediante la cual las autoridades migratorias clasifican a esta población, sino que incluyen otras como las experiencias en el destino de quienes viven solos y buscan trabajo o trabajan en diferentes circunstancias y condiciones, como el caso de los adolescentes de nuestro interés. Otras

\footnotetext{
${ }^{25}$ Resaltado de la autora.
} 
autoras y autores proponen hablar mejor de niñez independiente, que abarca la clasificación de la Observación No. 6, pero que no los nombra en función de su "separación" de personas adultas — padres/tutores y otros familiares- (Bhabha, 2008; Yaqub, 2009: 9-10). Según Jaqueline Bhabha (2008: 2):

Se puede definir a los niños y las niñas migrantes independientes como niños y niñas que migran a través de las fronteras nacionales de forma separada - aunque no necesariamente divorciada - de sus familias e incluyen dentro de esta definición cuatro categorías generales definidas por el propósito primordial del viaje:

a. Niños y niñas que viajan en busca de oportunidades, ya sean educativas o relacionadas con el empleo.

b. Niños y niñas que viajan para sobrevivir - para escapar de la persecución o la guerra, el abuso familiar, la extrema pobreza.

c. Niños y niñas que viajan para la reunión familiar — para unirse con familiares documentados o indocumentados que ya han migrado.

d. Niños y niñas que viajan en contexto de explotación [incluida la trata].

Estos grupos no son mutuamente excluyentes. Al igual que los adultos, los niños y las nińas viajan de manera independiente por razones que pueden superponerse. ${ }^{26}$

Además, hay que agregar que en muchos de estos casos se viaja sin documentación migratoria o no tienen la documentación apropiada para hacerlo (Chávez y Menjívar, 2010).

Los adolescentes de nuestro interés son considerados como migrantes independientes, una modalidad de migración sin acompańamiento, que no implica que sean personas sin la protección o el cuidado de familiares, pero sí que son personas que se involucran en distinto grado en la decisión de migrar, así como en decisiones durante

${ }^{26}$ Traducción libre. Children ha sido traducido como "niños y niñas". Valga aclarar que se trata de personas menores de 18 años, de acuerdo con la definición de nińez. Por lo tanto, bajo esta denominación se incluye a adolescentes. 
el proceso migratorio mismo, por lo que su punto de vista sobre la migración y su agencia son cruciales para comprender sus experiencias en la migración laboral.

\section{Adolescentes de Guatemala que remontan obstáculos y trabajan en México}

Para muchos adolescentes guatemaltecos, migrar desde sus comunidades para buscar trabajo en México constituye una experiencia vital. Estas experiencias pueden ser transicionales o no hacia otra fase de sus vidas, en el sentido de pasar a "adultos"; para algunos puede ser continuidad de una experiencia más larga que empezó desde una edad más temprana y que los propios adolescentes la pueden estar considerando como un camino hacia otra fase de sus vidas. En cualquier caso, interesa comprender qué es lo que los propios adolescentes piensan al respecto, qué los motiva, considerando su perspectiva.

Lo que revelan los relatos que analizamos para este artículo en particular es que hay adolescentes que asumen responsabilidades, toman decisiones, tienen claridad respecto al objetivo de su migración y de su trabajo en Chiapas, están expuestos a distintos riesgos, trabajan en condiciones precarias, y deben desplegar estrategias para su autoprotección así como la de sus amigos o familiares, si es que vienen en compañía de quienes tienen similares edades y también trabajan en parecidas circunstancias y actividades. Sobre esos casos, queremos puntualizar. Eso no implica que no haya otras experiencias en las que personas adolescentes puedan estar en condiciones de explotación o de vulneración y que la posibilidad de ejercer su agencia esté restringida.

Si bien no tenemos un conocimiento muy amplio sobre la situación de las personas “menores de 18 años” procedentes de Guatemala —y, más recientemente, pero en menor número, de otros países- que trabajan en la región Soconusco y en localidades fronterizas de esta o de otras regiones de la llamada frontera sur de México, en los últimos años se ha avanzado hacia una aproximación a sus experiencias. Ya en 1995, Aura Marina Arriola se refería a la niñez guatemalteca trabajando en diversas actividades en la ciudad de Tapachula. En el año 2000, como parte de una tipología de la migración femenina, en El Colegio de la Frontera 
Sur, Ecosur, llamábamos la atención sobre la presencia, como grupo de migrantes laborales, de "los niños y las nińas que se ocupan en servicios como ayudantes, cargadores, lustradores de calzado" (Ángeles y Rojas, 2000: 139). Un poco después llevamos a cabo un estudio específico sobre menores de edad que trabajan en actividades agrícolas (Rojas y Ángeles, 2002) y un estudio sobre niñez en municipios fronterizos de la región Soconusco (Rojas y Ángeles, 2003). A lo largo de la siguiente década se han llevado a cabo estudios específicos sobre las condiciones de vida y de trabajo enfocada a la niñez trabajadora en el sector primario y en el terciario (ver, por ejemplo, Casillas, 2006; Girón, 2010; López, 2012; Wilson, 2012; Zapata et al., 2013; Rivera, 2014). En el caso de niñas y adolescentes que trabajan en los hogares se han llevado a cabo algunos informes y estudios específicos, sin que necesariamente se focalicen en este grupo de edades sino en general en quienes participan en dicha actividad (ver, por ejemplo, Blanco, 2012). ${ }^{27}$

Con la descripción que hacía Aura Marina Arriola (1995), teníamos algunas evidencias de la diversidad de actividades en las que trabajaban niñas, niños y adolescentes de Guatemala en Tapachula. Actualmente, podemos tener una mejor idea de la inserción laboral mediante la Encuesta de Migración en la Frontera Sur, Emif Sur 2015, que, como la propia encuesta lo evidencia, es diversificada, sin que ello implique que se esté registrando un proceso de diversificación de oficio u ocupaciones. La diversidad ya existía y es necesario documentarla históricamente, pues la presencia de menores de edad que trabajan no es nueva ni mucho menos reciente (Arriola, 1995; Ángeles y Rojas, 2000; Girón, 2010). La encuesta capta registros de eventos de movilidad, por lo que hay que ser cautos en no usar esta fuente para hablar de volúmenes de trabajadores. ${ }^{28} \mathrm{~A}$ manera de ilustración, en 2015 se registraron 12,715

\footnotetext{
${ }^{27}$ Según cálculos propios con base en los datos de Emif Sur 2015, y a modo de ilustración, las mujeres trabajadoras en hogares, mayores de 15 pero menores de 18 años, representan sólo $2.7 \%$ del total de cruces de mujeres en dicha actividad captados a lo largo del año.

${ }^{28}$ En teoría, mediante los registros administrativos del INM, se podría tener una idea de la presencia de adolescentes de dieciséis y diecisiete ańos a quienes se les expide una tarjeta de trabajador fronterizo para desempeñar alguna actividad, previa carta de oferta de trabajo. Sin embargo, su número es muy bajo. Lo cual puede estar dando una idea de un subregistro de esta participación, o bien que ha descendido el número de personas que se documentan, como ya lo he expuesto en Rojas, 2017.
} 
cruces de trabajadores menores de dieciocho años que dicen ser residentes en Guatemala y que trabajaron en Chiapas, 3\%, de un total de 472,916 cruces. Dos tercios, $65 \%$, de esos cruces corresponden a casos de trabajadoras/es en actividades agropecuarias; $9.3 \%$ a trabajadores/as en el comercio; $5.7 \%$ a trabajadoras/es en servicios domésticos; $5.6 \%$ a trabajadores/as en la construcción; $5.3 \%$ a vendedores/as ambulantes; $5.2 \%$ a trabajadores/as industriales, y $4.1 \%$ a trabajadoras/es en oficios diversos - que incluyen vigilantes; conductores y ayudantes de conductores; ayudantes de preparación de alimentos; trabajadores en paquetería, entre otros ${ }^{29}$. Del total de cruces realizados por menores de edad, casi $82 \%$ corresponde a quienes permanecen en Chiapas más de 24 horas; $69 \%$ a quienes permanecen entre un mes y hasta un año. Desagregados por sexo, alrededor de $10 \%$ del total de cruces de menores de edad corresponde a mujeres. Por lugar de origen, 62\% corresponde a cruces realizados por menores de edad procedentes de Huehuetenango; 24\% de San Marcos y 10\% de Quetzaltenango, entre otros departamentos. Por uso de documento migratorio: $27 \%$ de los cruces son de menores de edad que no usan algún documento de este tipo; $40 \%$ utiliza tarjeta de visitante regional y $33 \%$ emplea tarjeta de trabajador fronterizo.

Entre los quince adolescentes que participaron en el taller, nueve señalaron que trabajaban vendiendo dulces, pero en la modalidad conocida como "chicleros", que es preferida por algunos porque les permite autoadministrarse. Dos trabajaban vendiendo dulces de azúcar conocidos como algodones, en una relación subordinada laboral. Otros trabajaban como: ayudantes en la preparación de alimentos, lustrador de zapatos — conocido como "bolero"-, ayudante de albañil y ayudante de veterinaria. Pero, en su trayectoria, al momento de la entrevista, varios habían desempeñado más oficios que el número de veces que habían llegado a Tapachula. Algunos tenían alrededor de cinco años de experiencia trabajando en esta ciudad. Al menos uno de ellos trabajó primero en las fincas, pero varios procedían de zonas rurales donde habían sido trabajadores familiares o jornaleros.

\footnotetext{
${ }^{29}$ Cálculos propios con base en datos de Emif Sur 2015. Cuestionario Procedentes de México (Colef et al., s.f.). Se agradece a Humberto Martínez García el procesamiento de datos de Emif Sur para esta sección.
} 
Los quince adolescentes son originarios de los departamentos de Huehuetenango y San Marcos que, según el Programa de Naciones Unidas para el Desarrollo, PNUD, con base en la edición 2014 de la Encuesta Nacional de Condiciones de Vida, Encovi, están ubicados en tercero y quinto lugar con mayor porcentaje de población en situación de pobreza multidimensional entre los 22 departamentos que componen Guatemala: $85.3 \%$ y $82.6 \%$, respectivamente (PNUD, s.f.). En su orden, estos adolescentes son de municipios del departamento de San Marcos: Concepción Tutuapa, San Marcos y Tacaná, con una tasa de pobreza total rural de $91.9 \%, 76.4 \%$ y $88.8 \%$, respectivamente, y tasa de pobreza extrema rural de $37.4 \%, 18.7 \%$ y $37.8 \%$, respectivamente (INE, 2013).

Básicamente se trata de adolescentes que llegan a Chiapas y, en particular, a la ciudad de Tapachula a trabajar porque hay opciones para hacerlo, aunque lo que ganen sea poco: "allá con nosotros casi no se consigue mucho trabajo" (León, 17 años) ${ }^{30}$. Hay varias motivaciones que pueden estar vinculadas entre sí, pero aquí destacamos: 1. seguir estudiando, pero no tienen los recursos para hacerlo -algunos estudian y otros se ven obligados a suspender un año para retomar al año siguiente-; mientras que otros ya no pueden seguir haciéndolo o consideran que con la primaria es suficiente para lo que quieren hacer en su futuro. 2. contar con algo para comprar su ropa o darse algún gusto, y 3. ayudar a sus padres y a sus hermanos con algún recurso.

Edmundo, de 15 ańos, originario de Cuilco, departamento de Huehuetenango, había llegado por tercera ocasión a Tapachula durante las vacaciones para trabajar y ayudarse con algunos gastos. Él ya había terminado su primer ańo de secundaria y quería seguir estudiando, pero su padre acababa de separarse de la familia, por lo que había decidido dejar la escuela un año mientras trabajaba. Tenía la firme intención de reanudar sus estudios al cabo de ese año:

yo tenía papá, pero mi papá lo dejó a mi mamá. Sí, mi mamá está sola ahorita y yo mismo estoy haciendo la lucha de tener un recurso para seguir mi estudio.

\footnotetext{
${ }^{30}$ En este artículo se usan pseudónimos con el propósito de preservar la identidad de los adolescentes. Éste no fue el caso para el libro de divulgación (Rojas, 2014), donde los participantes solicitaron que sus nombres de pila figuraran.
} 
Brandon, de 17 años, ya no vive en su aldea sino en la cabecera del municipio de San Marcos, a donde se fue después de terminar la secundaria para seguir estudiando y ser maestro, ${ }^{31}$ y si se puede ir a la universidad. Durante las vacaciones llega a Tapachula donde trabaja vendiendo dulces y así contar con algún ingreso:

... mi papá, cuando terminé mi secundaria, me habló ... si yo tenía la decisión de poder seguir estudiando, pues. Tuve que pensar, pues, porque... pensar en lo más grande, pues. Digamos, yo pensé antes en mis estudios, cómo sería mi profesión. Entonces me decidí; porque no hay más ... Entonces, decidí mi carrera [como maestro], y ahora eso, y ahora ya, digamos, que ya voy a medias.

Los adolescentes que tienen más años de llegar a Tapachula narran cómo se fue dificultando el cruce de la frontera. Misael, de 17 años, de San Marcos, viajó por primera vez a Tapachula a trabajar cuando tenía 12 años —en 2007-. En 2010, dice que comenzaron a pedir el permiso "para pasar". Su tío le ayudó a hacer el trámite, en ese entonces, de la Forma Migratoria de Visitante Local. Algunos de los adolescentes, como Misael o como Olegario, de 15 ańos, podían cumplir con el requisito de llevar a los padres o a un familiar adulto y hacer el trámite de un documento de visitante regional, mas no de trabajo. Para otros adolescentes, como Milton, de 17 ańos, también de San Marcos, que vive más lejos de la línea fronteriza, hacer ese trámite era muy difícil y, por eso, daba "la gran vuelta" para poder llegar a Tapachula, desafiando el control migratorio pero arriesgándose a sufrir un accidente $o$ un asalto. ${ }^{32} \mathrm{~A}$ otros les resultaba aún más difícil, como a Naum, de 16

\footnotetext{
${ }^{31}$ En marzo de 2016, en Concepción Tutuapa, San Marcos, Guatemala, organizamos la presentación del libro de divulgación sobre niñez y adolescentes guatemaltecos que trabajan en Chiapas (Rojas, 2014). Al finalizar la presentación en una escuela de educación primaria, uno de los maestros intervino para relatar que él se veía reflejado en algunas de esas historias porque había sido uno de esos adolescentes que viajaba a Tapachula para poder ayudarse con algún recurso para estudiar. Se trataba de una historia similar a la de Brandon.

${ }^{32}$ No se incluye la descripción de la ruta ni de los lugares de cruce porque no es el propósito de nuestro trabajo, pero, además, porque algunos adolescentes manifestaron temor al respecto. Ya en otro texto hemos señalado el dilema ético de visibilizar lo que expresamente se quiere invisibilizar como una estrategia de confrontar (Rojas y De Vargas, 2014).
} 
años, originario de Concepción Tutuapa, huérfano de padre y madre que creció con una familia adoptiva, aunque "a la mera hora" le dijeron: "no somos tus papás, pero te ayudamos a crecer". Sólo pudo cursar hasta el cuarto año de primaria, aun así no se ha quedado inactivo. Ha trabajado en varios lugares y quiere llegar lejos con su trabajo. Por eso, decidió buscarlo en Ciudad de Guatemala, luego en Cancún y más tarde en Tapachula; como no tenía documento de migración, cruzaba por el río Suchiate.

$\mathrm{N}$ : Yo paso por la frontera, por el río ... por el mero río, porque no hay de otra. No tengo papeles ni credencial, y sin un documento no se puede. $\mathrm{E}:$ ¿Has intentado sacar documentos? ¿Alguien te ha dicho? ¿Has preguntado? $\mathrm{N}$ : Sí, he preguntado, pero no tengo tiempo para sacar. Bueno, tal vez tiempo, pero no puedo porque nada tengo prueba de que... alguien me ayude. Yo solito pienso de cómo le puedo hacer, por eso me vengo para acá así.

Muchos de estos adolescentes —incluyendo a otros que no participaron en el taller - tuvieron que aprender que la frontera se erigió en límite, en demarcación, y que ya no la podían cruzar como cuando se usaba el "pase local" o se hacía sin documento migratorio, por lo que se vieron forzados a caminar largos trayectos para poder llegar a Tapachula - por el río o por la montańa- y que debían tratar de pasar desapercibidos y autoprotegerse, entre otras acciones.

\section{Reflexiones finales}

Las y los adolescentes de Guatemala que llegan a trabajar por temporadas a localidades fronterizas en México se ocupan en distintas actividades. En el caso de los adolescentes que participaron en el taller al que aludimos más arriba, la mayor parte combina el estudio con el trabajo, ya sea porque estudian o piensan seguir haciéndolo, pero también hay quienes no estudian, sea porque ya no pudieron hacerlo o porque así lo decidieron. Las narraciones nos permiten un acercamiento a su vida cotidiana y a las situaciones que deben enfrentar cuando quieren trabajar en la ciudad de Tapachula, en medio de 
restricciones que se han impuesto para cruzar la frontera. Tapachula y la región Soconusco, históricamente, han sido lugares a los que adolescentes de ambos sexos de Guatemala, que viven relativamente cerca de la frontera, llegan a buscar trabajo porque hay esa posibilidad. Se ha extendido la idea de que estos adolescentes son víctimas de trata laboral, que algunos participan en la venta de drogas, que otros no son de fiar, que son posibles delincuentes, etcétera. Esa, al menos, no es la situación de los adolescentes que participaron en el taller ya aludido. Posiblemente, en la región haya casos de éstos, pero eso no implica establecer una etiqueta que conduzca a la generalización, a la estigmatización y a la imposición rígida de medidas restrictivas que lejos de reconocer a las personas como sujetas de derechos, no sólo las victimiza o criminaliza, sino que las expone de facto a una mayor vulnerabilidad a la explotación y a la exclusión social.

Las restricciones relacionadas con la edad mínima para trabajar, la erradicación del trabajo infantil y la edad autónoma para hacer trámites deben ser revisadas, considerando el contexto social y cultural, pero sobre todo escuchando la voz de los y las adolescentes, quienes llegan a México buscando opciones de trabajo y mejorar en algo sus ingresos y los de sus familias. Los adolescentes que participaron en el taller ya mencionado son plenamente conscientes de las dificultades que enfrentan en este proceso, pero como decía Emanuel, de 15 ańos, de Tacaná, le "echan ganas" y trabajan duro: tienen largas jornadas de trabajo; cambian de trabajo buscando opciones más independientes y algún oficio que les guste o en el que consideren que hay alguna ventaja o mejora comparado con otro. Estas experiencias deben ser escuchadas y tomadas en cuenta en la formulación de políticas públicas y en su aplicación, como dice Harriot Beazley, para que los derechos de la niñez y la adolescencia no se sigan violando en nombre de "la protección" (2015: 306) y que se invisibilicen las situaciones de precariedad laboral en las que de hecho se encuentran, enfrentando, además, múltiples obstáculos, y viéndose forzados a remontar diferentes fronteras. En ese mismo sentido, estamos de acuerdo con Jaqueline Bhabha en que "la vulnerabilidad y la necesidad de protección son sólo un elemento de la agenda de política social; la otra función es facilitar la inclusión, 
la promoción de oportunidades y el reconocimiento de la capacidad de acción autónoma responsable para la participación infantil en la formulación de políticas" (Bhabha, 2008: 2).

\section{Bibliografía citada}

Ángeles Cruz, Hugo y Martha Rojas Wiesner, 2000, "La migración femenina internacional en la frontera sur de México", Papeles de Población, Año 6, núm. 23, pp. 127-151, enero-marzo.

Ariza, Marina, 2005, "Juventud, migración y curso de vida. Sentidos y vivencias de la migración entre los jóvenes urbanos mexicanos”, en Marta Mier y Terán y Cecilia Rabell (coordinadoras), Jóvenes y niños. Un enfoque sociodemográfico, LIX Legislatura de la Cámara de Diputados, Flacso, IIS UNAM, Porrúa, México, D.F., pp. 39-70.

Arriola, Aura Marina, 1995, Tapachula, "La perla del Soconusco": ciudad estratégica para la redefinición de las fronteras, Flacso, Guatemala.

Basok, Tanya, Danièle Bélanger, Martha Luz Rojas Wiesner y Guillermo Candiz, 2015, Rethinking Transit Migration. Precarity, Mobility, and Self-Making in Mexico, Palgrave Macmillan, Basingstoke, Hampshire, UK.

Basok, Tanya y Martha Luz Rojas Wiesner, 2017, "Precarious legality: regularizing Central American migrants in Mexico", en Ethnic and Racial Studies, disponible en http://www.tandfonline.com/ doi/abs/10.1080/01419870.2017.1291983?journalCode=rers20

Beazley, Harriot, 2015, "Multiple identities, multiple realities: children who migrate independently for work in Southeast Asia”, Children's Geographies, vol. 13, núm. 3, pp. 296-309.

Bhabha, Jaqueline, 2008, "Independent Children, Inconsistent Adults: International Child Migration and the Legal Framework", Discussion Paper, núm. 2, mayo, [en línea] disponible en https:// www.unicef-irc.org/publications/pdf/idp_2008_02.pdf [fecha de consulta: 2 de julio de 2017]. 
Bhabha, Jaqueline, 2011a, "From citizen to migrant: the scope of child statelessness in the twenty-first century", en Jaqueline Bhabha (editora), Children without a state: a global human rights challenge, Massachusetts Institute of Technology, Cambridge, MA, pp. 1-39.

Bhabha, Jaqueline (editora), 2011b, Children without a state: a global human rights challenge, Massachusetts Institute of Technology, Cambridge, MA.

Blanco, Blanca, 2012, "No me puedo dejar": negociación y resistencia en el empleo doméstico. Aproximación a la capacidad de agencia de las empleadas domésticas guatemaltecas en Tapachula, Chiapas, tesis de maestría, CIESAS, México.

Boehm, Deborah A., Julia Meredith Hess, Catie Coe, Heather RaeEspinoza y Rachel R. Reynolds, 2011, "Children, youth, and the everyday ruptures of migration", en Cati Coe, Rachel R. Reynolds, Deborah A. Boehm, Julia Meredith Hess y Heather Rae-Espinoza (editoras), Everyday ruptures: children, youth, and migration in global perspectives, Vanderbilt University, Nashville, TN, pp. 1-19.

Bourdin, Jean-Claude, 2010, "La invisibilidad social como violencia", Universitas Philosophica, Año 27, núm. 54, pp. 15-33.

Brachet, Julies, 2018, "Manufacturing Smugglers: From Irregular to Clandestine Mobility in the Sahara", The ANNALS of the American Academy of Political and Social Science, vol. 676, issue 1, pp. 16-35, https://doi.org/10.1177/0002716217744529

Caballeros, Álvaro, 2011, "Migración con rostro de niños, niñas y adolescentes”, Encuentro, núm. 90, pp. 84-93.

Casas-Cortes, Maribel, Sebastian Cobarrubias, Nicholas De Genova, Glenda Garelli, Giorgio Grappi, Charles Heller, Sabine Hess, Bernd Kasparek, Sandro Mezzadra, Brett Neilson, Irene Peano, Lorenzo Pezzani, John Pickles, Federico Rahola, Lisa Riedner, Stephan Scheel y Martina Tazzioli, 2014, "New Keywords: Migration and Borders", Cultural Studies, vol. 29, núm. 1, pp. 55-87, https://doi.org/10.1080/09502386.2014.891630. 
Casillas, Rodolfo, 2006, La trata de mujeres, adolescentes, niñas y niños en México. Un estudio exploratorio en Tapachula, Chiapas, Comisión Interamericana de la Organización de los Estados Americanos, Organización Internacional para las Migraciones, Instituto Nacional de las Mujeres, INM, México, D.F.

Castro M., Jorge, Alejandro Cussiánovich V., Luis Tejada R. y Jorge Valencia Corominas, 2009, Participación de los niños y niñas. Balance a los veinte años de la Convención, Instituto de Formación de Educadores de Jóvenes, Adolescentes y Niños Trabajadores de América Latina y El Caribe IFEJANT, Save The Children, Lima.

Ceriani Cernadas, Pablo (coordinador), 2013, Niñez detenida: Los derechos de los niños, niñas y adolescentes migrantes en la frontera México-Guatemala, Fontamara, México, D.F.

Chavez, Lilian y Cecilia Menjívar, 2010, "Children without borders: a mapping of the literature on unaccompanied migrant children to the United States", Migraciones Internacionales, vol. 5, núm. 3, pp. 71-111, enero-junio.

Consejo Nacional para Prevenir la Discriminación, Conapred, 2010, Documento informativo sobre trabajo infantil en México, Conapred, [en línea] disponible en http://www.conapred. org. $\mathrm{mx} /$ index.php? contenido=documento \&id=102\&id_ opcion $=45 \&$ op $=491$

Cruz Salazar, Tania, 2009, "Mudándose a muchacha. La emergencia de la juventud en indígenas migrantes”, en Graciela FreyermuthEnciso y Sergio Meneses Navarro (coordinadores), De crianzas, jaibas e infecciones. Indigenas del Sureste en la migración, Centro de Investigaciones y Estudios Superiores en Antropología Social, México, D.F, pp. 169-212.

De Vos, Jan, 2005, "La formación de la frontera entre México y Centroamérica", en Salvador Hernández Daumás (coordinador), Frontera sur de México: cinco formas de interacción entre sociedady ambiente, El Colegio de la Frontera Sur, Tapachula, pp. 15-20.

Dobson, Madeleine, 2009, "Unpacking children in migration research”, Children's Geographies, vol. 7, núm. 3, pp. 355-360. 
Esser, Florian, Meike S. Baader, Tanja Betz y Beatrice Hungerland, 2016, "Reconceptualising Agency and Children. An introduction", en Florian Esser, Meike S. Baader, Tanja Betz y Beatrice Hungerland (editores), Reconceptualising Agency and Children. New perspectives in Childhood Studies, Routledge, New York, pp. $1-14$.

Foucault, Michel, 2008, Tecnologías del yo y otros textos afines, Paidós, Buenos Aires.

Fuentes Camarena, Ma. Magdalena y José A. Moreno Mena, 2008, "Medidas antiinmigrantes, perjuicios potenciales en los menores migrantes", en Gloria Ciria Valdéz-Gardea (coordinadora), Achicando futuros. Actores y lugares de la migración, El Colegio de Sonora, Hermosillo, pp. 297-312.

Galindo, Carlos, 2009, Nosotros no cruzamos la frontera: los hijos estadounidenses de los migrantes mexicanos, Conapo, México, D.F.

Gallo Campo, Karla I., 2005, "Niñez migrante: blanco fácil para la discriminación”, en Juan Carlos Gutiérrez (coordinador) Memorias del Seminario Internacional. Los Derechos Humanos de los Migrantes, Programa de Cooperación sobre Derechos Humanos, México-Comisión Europea, Secretaría de Relaciones Exteriores, México, D.F., pp. 133-144.

Giddens, Anthony, 1995, La constitución de la sociedad: bases para la teoría de la estructuración, Amorrortu, Buenos Aires.

Girón, Carol, 2010, "Migrantes Mam entre San Marcos (Guatemala) y Chiapas (México)", en Alicia Torres (coordinadora), Niñez indigena en migración. Derechos en riesgo y tramas culturales, Flacso Ecuador, AECID, Unicef, Quito, pp. 227-310.

González Martín, Nuria, 2012, “Aspectos socio-jurídicos en torno a los menores migrantes no acompañados. El caso de México", en Gabriele Vestri y Nuria González Martín, Los menores de edad migrantes no acompañados y sus exigencias jurídicas. Un diálogo entre España y México, Centro Euro-Árabe de Estudios Jurídicos Avanzados, Universidad Pablo de Olavide, Sevilla, pp. 111-204. Instituto Nacional de Estadística, INE, 2013, Mapas de pobreza rural en Guatemala 2011, Gobierno de Guatemala, Banco Mundial, 
Guatemala, [en línea] disponible en https://www.ine.gob.gt/ sistema/uploads/2015/09/28/V3KUhMhfgLJ81 djtDdf6H2d7eNm0sWDD.pdf [fecha de consulta: 17 de agosto de 2017].

López Reyes, Yasmina Areli, 2012, "Niños, niñas y adolescentes: migrantes trabajadores guatemaltecos en la ciudad de Tapachula, Chiapas", Liminar. Estudios Sociales y Humanisticos, vol. X, núm. 1, junio, pp. 58-74.

Marquet Guerrero, Porfirio, 2014, "Fuentes y antecedentes del derecho mexicano del trabajo", en Patricia Kurczyn Villalobos (coordinadora), Derechos humanos en el trabajo y la seguridad social, Instituto de Investigaciones Jurídicas UNAM, pp. 243-280.

Musalo, Karen, Pablo Ceriani Cernadas y Lisa Frydman (editores), 2015, Niñez y migración en Centro y Norte América: causas, politicas, prácticas y desafios, University of California Hastings College of the Law, Universidad Nacional de Lanús, San Francisco, CA, Buenos Aires.

Naciones Unidas, 2005, Observación General No. 6. Trato de los menores no acompañados y separados de su familia fuera de su lugar de origen, Comité de Derechos del Niño, 1 de septiembre.

Organización Mundial de la Salud, OMS, s.f., "Desarrollo en la adolescencia”, [en línea] disponible en http://www.who.int/ maternal_child_adolescent/topics/adolescence/dev/es/ [fecha de consulta: 6 de julio de 2017].

Organización Internacional del Trabajo, OIT, y Organización Internacional de Empleadores, OIE, 2016, Herramienta de orientación de la OIT y la OIE sobre trabajo infantil destinada a las empresas. Cómo hacer negocios respetando el derecho de los niños a estar libres del trabajo infantil, OIT, OIE, Ginebra.

Rivera Farfán, Carolina, 2014, "Niños, niñas y adolescentes centroamericanos en el mercado laboral dela frontera GuatemalaMéxico: hacia la evidencia de una presencia encubierta y simulada”, en Carolina Rivera Farfán (coordinadora), Trabajo $y$ vida cotidiana de centroamericanos en la frontera suroccidental de México, CIESAS, México, D.F. 
Rojas Wiesner, Martha Luz, 2014, Narrativa y fotografía de niños y adolescentes trabajadores guatemaltecos en Tapachula, Chiapas, El Colegio de la Frontera Sur, San Cristóbal de Las Casas, Chiapas.

Rojas Wiesner, Martha Luz, 2017, "Movilidad de trabajadores agrícolas de Guatemala a la frontera sur de México en tiempos de control migratorio", EntreDiversidades. Revista de Ciencias Sociales y Humanidades, núm. 8, [en línea] disponible en http:// entrediversidades.unach.mx/index.php/entrediversidades/rt/ printerFriendly/358/684

Rojas Wiesner, Martha Luz y Álvaro Caballeros, 2015, Riesgos en la migración en tránsito irregular por México y mejores prácticas de protección a los transmigrantes, Documento de Trabajo núm. 1, Instituto Tecnológico Autónomo de México, México, D.F.

Rojas Wiesner, Martha Luz y Hugo Ángeles Cruz, 2002, Participación de mujeres y menores en la migración laboral agrícola guatemalteca a la región del Soconusco, Chiapas, Informe Técnico Final del proyecto SIBEJ 19990503017, El Colegio de la Frontera Sur, Tapachula (inédito).

Rojas Wiesner, Martha Luz y Hugo Ángeles Cruz, 2003, La situación de los niños, las niñas y adolescentes en los municipios fronterizos del Soconusco, Chiapas, 2002, Informe Final del Proyecto apoyado por Unicef y el Instituto de Desarrollo Humano del Gobierno del Estado de Chiapas, El Colegio de la Frontera Sur, Tapachula (inédito).

Rojas Wiesner, Martha Luz y María de Vargas, 2014, "Strategic Invisibility as Everyday Politics for a Life with Dignity: Guatemalan Women Migrants' Experiences of Insecurity at Mexico's Southern Border", en Thanh-Dam Truong, Des Gasper, Jeff Handmaker, Sylvia I. Bergh (editores), Migration, Gender and Social Justice. Perspectives on Human Insecurity, Springer, Berlin, pp. 193-211.

Sin Fronteras (coordinadora), 2008, Cambiando perspectivas: de la gestión de flujos hacia la construcción de políticas de migración con enfoque de desarrollo, Sin Fronteras IAP, México, D.F. 
Tyrrel, Naomi, 2011, “Children's agency in family migration decision making in Britain", en Cati Coe, Rachel R. Reynolds, Deborah A. Boehm, Julia Meredith Hess y Heather Rae-Espinoza (editores), Everyday ruptures: children, youth, and migration in global perspectives, Vanderbilt University, Nashville, TN, pp. 23-38.

Valdéz-Gardea, Gloria Ciria (coordinadora), 2011, La Antropología de la migración: niños y jóvenes migrantes de la globalización, El Colegio de Sonora, Universidad Autónoma de Sinaloa, Hermosillo.

Velasco, Juan Carlos, 2016, El azar de las fronteras. Politicas migratorias, ciudadanía y justicia, Fondo de Cultura Económica, México.

Wilson González, Jania Elizabeth, 2012, Entre la plebe: patojos cortando caña, adolescentes guatemaltecos cortadores de caña en la agroindustria azucarera de Huixtla, Chiapas: tácticas y vida cotidiana, tesis de maestría, CIESAS, San Cristóbal de Las Casas, Chiapas, septiembre.

Zapata Martelo, Emma, Rosa Martínez Ruiz y Gustavo E. Rojo Martínez (coordinadores), 2013, Escenarios del trabajo infantil. Diversos estudios de caso, Universidad Autónoma Indígena de México, Colegio de Postgraduados, México, D.F.

Unicef, 2011, "La adolescencia temprana y tardía", en Punto de mira, [en línea] disponible en https://www.unicef.org/spanish/ sowc2011/pdfs/La-adolenscencia-temprana-y-tardia.pdf [fecha de consulta: 10 de julio de 2017].

Unicef México e INM/Dirección General de Protección al Migrante y Vinculación, 2013, "Derechos de niños, niñas y adolescentes migrantes", en Laprotección de los derechos humanos de laspersonas migrantes: una guía para las y los servidores públicos, Unidad de Política Migratoria, Instituto Nacional de Migración, Acnur, México, D.F., pp. 189-210.

Yaqub, Shanin, 2009, "Independent child migrants in developing countries: unexplored links in migration and development", Innocenti Working Paper, enero. 


\section{Referencias electrónicas}

Consejo Ciudadano del Instituto Nacional de Migración, CCINM, 1a Reunión del Grupo de Trabajo sobre las Tarjetas de Visitante Regional, Minuta 7 de julio de 2015, [en línea] disponible en https://www.gob.mx/cms/uploads/attachment/file/25229/Minuta_TVR_Honduras_y_El_Salvador.pdf [fecha de consulta: 16 de febrero de 2018].

Decreto por el que se expide la Ley de Migración, Diario Oficial de la Federación, DOF, Ciudad de México (25 de mayo de 2011), [en línea] disponible en http://www.dof.gob.mx/nota_detalle.php? codigo $=5190774 \&$ fecha $=25 / 05 / 2011$ [fecha de última consulta: 6 de julio de 2017].

Decreto por el que se reforma la fracción III del apartado $A$ del articulo 123 de la Constitución Política de los Estados Unidos Mexicanos, Diario Oficial de la Federación, Ciudad de México (17 de junio 2014), [en línea] disponible en http://www.dof.gob.mx/ nota_detalle.php?codigo $=5348865 \&$ fecha $=17 / 06 / 2014$ [fecha de consulta: 2 de julio de 2017].

Decreto por el que se reforman y derogan diversas disposiciones de la Ley Federal del Trabajo, en materia de trabajo de menores, Diario Oficial de la Federación, Ciudad de México (12 de junio de 2015), [en línea] disponible en http://www.dof.gob.mx/nota_ detalle.php? codigo $=5396526 \&$ fecha $=12 / 06 / 2015$ [fecha de consulta: 2 de julio de 2017].

El Colegio de la Frontera Norte, Secretaría del Trabajo y Previsión Social, Consejo Nacional de Población, Unidad de Política Migratoria, Secretaría de Relaciones Exteriores, Consejo Nacional para Prevenir la Discriminación, s.f., "Emif Sur", en Encuestas sobre Migración en las fronteras norte y sur, [en línea] disponible en http://www.colef.mx/emif [consultado en distintas fechas de 2017].

Ley Federal de Derechos, LFD, Diario Oficial de la Federación, Ciudad de México (última reforma: 7 de diciembre de 2016), [en línea] disponible en http://www.diputados.gob.mx/LeyesBiblio/ pdf/107_221216.pdf [fecha de consulta: 6 de julio de 2017]. 
Ley Federal del Trabajo, LFT, Diario Oficial de la Federación, Ciudad de México (última reforma: 12 de junio de 2015), [en línea] disponible en https://www.gob.mx/cms/uploads/attachment/ file/156203/1044_Ley_Federal_del_Trabajo.pdf [fecha de última consulta: 17 de julio de 2017].

Ley para la Protección de los Derechos de Niños, Niñas y Adolescentes, LPDNNA, Diario Oficial de la Federación, Ciudad de México, (última reforma: 19 de agosto de 2010), [en línea] disponible en http://www.senado.gob.mx/comisiones/desarrollo_social/ docs/marco/Ley_PDNNA.pdf [fecha de consulta: 11 de julio de 2017].

Lineamientos para trámites y procedimientos migratorios, Diario Oficial de la Federación, Ciudad de México (8 de noviembre de 2012), [en línea] disponible en http://dof.gob.mx/nota_detalle.php?c odigo $=5276967 \&$ fecha $=08 / 11 / 2012$ [fecha de última consulta: 17 de julio de 2017].

Naciones Unidas, s.f., "11. Convention on the Rights of the Child", en Chapther IV: Human Rights of Multilateral Treaties Deposited with the Secretary-General, Treaty Collection, United Nations, [en línea] disponible en https://treaties.un.org/Pages/ViewDetails. aspx?src=TREATY\&mtdsg_no $=\mathrm{IV}-11$ \&chapter $=4 \&$ clang $=$ en [fecha de consulta: 2 de julio de 2017].

Oficina del Alto Comisionado de las Naciones Unidas para los Derechos Humanos, OHCHR, s.f., "Observaciones Generales", Vigilancia del ejercicio de los derechos del niño, Comité de los Derechos del Niño, [en línea] disponible en http://www2.ohchr.org/ spanish/bodies/crc/ [fecha de consulta: 9 de agosto de 2017].

Organización Internacional del Trabajo, OIT, 2014, "El empleo informal en México: situación actual, políticas y desafíos", en Notas sobre formalización, OIT, [en línea] disponible en http:// www.ilo.org/wcmsp5/groups/public/---americas/---ro-lima/ documents/publication/wcms_245619.pdf [fecha de consulta: 7 de julio de 2017]. 
Organización Internacional del Trabajo, OIT, s.f., "Ratificaciones de México", en NORMLEX. Information System on International Labour Standards, OIT, [en línea] disponible en http:// www.ilo.org/dyn/normlex/es/f?p=1000:11200:0::NO:1120 0:P11200_COUNTRY_ID:102764 [fecha de consulta: 6 de julio de 2017].

Programa de Naciones Unidas para el Desarrollo, PNUD, s.f., "Indicadores de la pobreza multidimensional", [en línea] disponible en http://desarrollohumano.org.gt/estadisticas/estadisticas-pobreza-y-desigualdad/indice-de-pobreza-multidimensional-segunnivel-de-privaciones-por-departamento/ [fecha de consulta: 17 de agosto de 2017].

Sistema para el Desarrollo Integral de la Familia del Estado de Chiapas, DIF Chiapas, s.f., Centro de Atención a Niñas, Niños y Jóvenes Migrantes (Centro de Día), [en línea] disponible en http:// www.difchiapas.gob.mx/\#servicios_1 [consultado en distintas fechas en 2014 y 2017].

Unidad de Política Migratoria de la Secretaría de Gobernación, UPM, s.f., "Boletines Estadísticos", [en línea] disponible en http:// www.politicamigratoria.gob.mx/es_mx/SEGOB/Boletines_ Estadisticos [consultado en varias fechas; última consulta en agosto de 2017]. 